\title{
APARATO BUROCRÁTICO E OS NÚMEROS DO ENSINO: UMA ABORDAGEM HISTÓRICA
}

\author{
NATÁLIA GIL \\ Escola de Artes, Ciências e Humanidades da Universidade de São Paulo \\ natalia.gil@uol.com.br
}

\begin{abstract}
RESUMO
Neste texto procurou-se sistematizar as iniciativas que contribuíram para a constituição de um sistema nacional de estatísticas educacionais no Brasil, especialmente no período de l 87 I a 193 I. São indicados esforços, realizações e disputas de idéias que concorreram para a consolidação das informações quantitativas sobre educação como instrumento de descrição da "realidade", considerado legítimo e como guia das ações do Estado.

HISTÓRIA DA EDUCAÇÃO - DADOS ESTATIŚSTICOS - EDUCAÇÃO - SISTEMA NACIONAL DE ESTATÍSTICAS EDUCACIONAIS
\end{abstract}

\begin{abstract}
THE BUROCRATIC APPARATUS AND EDUCATIONAL NUMBERS: A HISTORICAL APPROACH. The aim of this text was to systematize the initiatives which contributed to the creation of a National System of Educational Statistics in Brazil, given special attention to the period 187 I1931. The efforts, the accomplishments and some of the controversies that marked the process of consolidation of quantitative information as a legitimate tool to describe the reality and to guide State actions are presented and discussed.

HISTORY OF EDUCATION - STATISTICAL DATA - EDUCATION - NATIONAL SYSTEM OF EDUCATIONAL STATISTICS
\end{abstract}


Este trabalho procurou sistematizar as iniciativas que contribuíram para a constituição de um sistema nacional de estatísticas educacionais no Brasil, com especial atenção ao período compreendido entre |87| e 1931, em que se concentraram os principais eventos relativos a esse processo. Buscou-se explicitar os fatos que marcaram sua história e, assim, oferecer subsídios para a realização de estudos posteriores que discutam e/ou utilizem como fonte os dados estatísticos sobre educação. São indicados esforços, realizações e algumas das disputas de idéias que fizeram parte do processo de consolidação das informações quantitativas sobre educação como instrumento considerado legítimo, de descrição da "realidade", e como guia das ações do Estado.

As informações contidas neste estudo foram obtidas tanto em textos contemporâneos ao momento dos acontecimentos descritos, em sua grande parte produzidos por figuras de relevo na administração pública que tinham interesse no aperfeiçoamento das estatísticas e que colaboraram muito para a riqueza do debate no período, quanto em análises posteriores, que lançam um olhar retrospectivo para esses processos. Desse modo, justifica-se a reiterada referência, no texto, a alguns desses autores. Cabe lembrar a relevância da Revista Brasileira de Estudos Pedagógicos, publicação do Instituto Nacional de Estudos e Pesquisas Educacionais - Inep -, para este esforço de sistematização. Periódico vinculado ao Ministério da Educação, preocupou-se desde que foi criado, em 1944, com a discussão das questões referentes à organização do sistema educativo, entre as quais figurava a estatística. Também a Revista Brasileira de Estatística, periódico do Instituto Brasileiro de Geografia e Estatística - IBGE -, foi de grande valia. Criado em 1940, este periódico acabou por se constituir em espaço privilegiado de debate acerca das questões relativas à estatística e à demografia.

Importa igualmente destacar que, embora a história das estatísticas educacionais brasileiras seja, ainda, pouco estudada na área de História da Educação, algumas iniciativas têm, nos últimos anos, contribuído para reverter essa situação. Desse modo, cabe destacar a mesa-redonda "Alfabetização, escolarização e processos de contagem e ordenação de populações na construção do Estado moderno: os casos do Brasil e de Portugal", que se realizou no $4^{\circ}$ Congresso Luso-Brasileiro de História da Educação em 2002 (Porto Alegre), e da qual participaram Denice Barbara Catani, Cynthia Pereira de Sousa e Luciano Mendes de Faria Filho. Outro dado importante 
foi a publicação, em 2005, do livro Modernidade, educação e estatísticas na Ibero-América nos séculos XIX e XX: estudos sobre Portugal, Brasil e Galiza, organizado por António Candeias. Publicado em Portugal, o livro traz também artigos de autores brasileiros. Além disso, há alguns trabalhos dispersos em periódicos e eventos da área, principalmente de autoria de Luciano Mendes de Faria Filho, que têm insistido sobre a necessidade de ampliar esta linha de pesquisa. Por fim, vale dizer que eu mesma tenho pesquisado sobre tema sob orientação da professora Denice Barbara Catani, no mestrado e também no doutorado.

\section{SOBRE SOLDADOS E IMPOSTOS: AS PRIMEIRAS INICIATIVAS}

Durante o período colonial, os levantamentos quantitativos feitos no Brasil empenhavam-se em descrever as terras sob domínio lusitano e mensurar o número de seres que as habitavam, mediante estimativas grosseiras com fins essencialmente militares e fiscais. Já os dados populacionais eram incipientes e provinham dos registros eclesiásticos, ou seja, referiam-se aos batizados, casamentos e óbitos (Marcílio, 1986).

modo pelo qual se procedeu à independência do Brasil definiu, em vários aspectos, uma continuidade da ordem estabelecida pelo governo português no Estado nacional que então se constituía. Isso está presente também nos levantamentos populacionais realizados até o período regencial, cujos procedimentos e preocupações eram os mesmos que tinham orientado tais esforços por parte da Coroa portuguesa. Os próprios funcionários encarregados dos censos eram muitas vezes os mesmos que no momento anterior à independência tinham respondido por esses trabalhos. As categorias censitárias explicitavam permanências significativas com relação ao período precedente, revelando a hierarquia social herdada da Colônia e a preocupação em medir as forças do Estado para o recrutamento militar (Botelho, 1998; Vianna, 1986).

A partir da Regência passam a figurar nos trabalhos estatísticos sobre a população outras preocupações além daquelas relacionadas ao poderio militar e à cobrança de impostos. Com a instituição do Estado imperial brasileiro, tornou-se necessário conhecer o número de habitantes de cada paróquia para que fosse possível realizar eleições e levar a efeito algumas políticas que visavam assegurar o bem-estar da população, como as relacionadas ao fim 
da escravidão, à falta de saneamento nas grandes cidades e à criação de um sistema de instrução pública.

Foucault (1978) ressalta, para o caso europeu, que com a consolidação dos Estados nacionais no século XIX surge o conceito de população como eixo organizacional para as questões públicas. As técnicas e estratégias de governo voltam-se, então, para o grupo populacional, surgindo o interesse pelo conhecimento dos habitantes de determinado território. Embora quando do surgimento dos Estados nacionais a referência ao bem-estar social estivesse associada essencialmente aos itens que tornavam possível o funcionamento do Estado nos novos moldes, foi esta mudança de perspectiva que evoluiu para as preocupações sociais atuais. Tal situação também pode ser identificada no Brasil quando se analisam as categorias utilizadas nos levantamentos estatísticos realizados no Império. Gradativamente passam a ocupar significativo espaço as preocupações com as condições de vida da população brasileira em um período no qual se buscava delinear um perfil nacional para o Estado recémindependente.

Surge aí a necessidade de pensar o Brasil como uma nação em oposição à sua condição anterior de submissão à metrópole. Para tanto, importava "conhecer-se a fim de garantir seu domínio sobre o território que lhe cabia, mas também para determinar quem pertencia à comunidade que começa a ser imaginada" (Botelho, 1998, p.7)'. Nesse sentido, muitos são os esforços empreendidos no século XIX pelo Império, a fim de se conhecer o efetivo da população. Tentou-se de muitos modos executar censos simultâneos e homogêneos, empreendimento que só logrou êxito em 1872, quando foi realizado o primeiro censo populacional moderno no Brasil.

\section{RECENSEAMENTO POPULACIONAL: A VISIBILIDADE DA NAÇÃO}

Em 1829 foi criada a Commissão de Estatística Geographica, Natural, Política e Civil com o intuito de sistematizar os esforços censitários que vinham sendo realizados por algumas das províncias. No entanto, as solicitações de

I. O entendimento do Estado-Nação como uma comunidade imaginada vem de BenedictAnderson (1989, p. 14), para quem a nação é "imaginada porque nem mesmo os membros das menores nações jamais conhecerão a maioria de seus compatriotas, nem os encontrarão, nem sequer ouvirão falar neles, embora na mente de cada um esteja viva a imagem de sua comunhão". 
funcionários e recursos feitas por esta comissão ao Império não foram atendidas, impedindo-a de levar a efeito seus trabalhos. De acordo com Vianna,

...a Commissão de Estatística Geographica teria fatalmente de tornar-se um aparelho inútil, apezar da indiscutivel competencia dos seus membros, pois era um orgam central sem meios de acção no interior do paiz, tendo por objectivo reunir e apurar dados para os quaes não existiam fontes informantes e ficando, portanto, improficuas as pesquisas por absoluta falta, imperfeição ou deficiencia dos elementos solicitados e raras vezes conseguidos, o que tornava quasi impossivel a regular e opportuna systematização dos algarismos colligidos. (1986, p. 175)

Assim, sem as condições necessárias para um mínimo funcionamento, em 1834 a comissão foi definitivamente desativada, não tendo conseguido produzir nada de efetivo.

Em I 852 houve a tentativa de realização do primeiro censo simultâneo do Império. Contando com legislação específica e dotação orçamentária, foi uma iniciativa bastante sistemática e rigorosa, que deveria fornecer informações acerca dos "nomes (exceto dos escravos), o estado conjugal, a idade, a condição (ingênuo, liberto ou escravo), o lugar do nascimento, a nação dos estrangeiros e a tribo dos indígenas, a profissão e a posição dentro do domicílio" (Botelho, 1998, p.43). A iniciativa não logrou êxito, uma vez que o referido censo teve sua realização suspensa antes mesmo que tivessem sido iniciados os trabalhos. Vale ressaltar que do regulamento deste primeiro projeto de censo populacional não constava nenhuma indagação acerca da educação ou dos níveis de instrução dos indivíduos.

Em 1872 foi feita nova tentativa de contagem da população, que resultou no Recenseamento Geral do Império, reconhecidamente o primeiro censo moderno brasileiro. Nesta ocasião foram previstas e efetivamente coligidas informações acerca da instrução da população e da freqüência das crianças à escola. A regulamentação que conformou os trabalhos censitários desse ano definia, entre outras orientações, que no levantamento

....seriam declarados o nome, o sexo, a idade, a cor, o estado civil, a naturalidade, a nacionalidade, a residência, o grau de instrução primária, a religião, as 
enfermidades aparentes, o grau de parentesco ou de convivência de cada pessoa com o chefe da família e, para as crianças de 6 a 15 anos, a freqüência escolar. (Botelho, 1998, p.57, grifos meus)

As medidas de retomada da centralização do poder assumidas no Segundo Reinado favoreceram a organização da iniciativa de levantamento quantitativo dos habitantes do território brasileiro. Nesse período, voltava às mãos do governo central o aparelho administrativo e judiciário, diminuindose assim a autonomia das províncias. Sob responsabilidade do poder local, as estatísticas não tinham tido muitas chances de avanço, devido às precárias condições e poucos recursos de que dispunha a maioria das regiões do país. Passando a atribuição ao poder central, era possível conjugarem-se os esforços para tornar viável o plano de realização do censo da população do Império. À parte esta favorável situação interna para execução das estatísticas, crescia no cenário internacional a importância conferida às comparações entre os países por intermédio das estatísticas, o que se evidencia pelo crescente destaque dado, durante o século XIX, às Exposições Internacionais.

Desde | 85 |, quando foi realizada a Exposição de Londres, tais eventos constituíram-se em espaços privilegiados de celebração da sociedade capitalista industrial, da ciência e do progresso. Nessas ocasiões eram exibidos produtos industriais e artísticos, novidades tecnológicas e apresentados materiais e informações acerca da situação de cada país participante quanto a diversos aspectos da vida nacional. As Exposições Internacionais eram momentos de exibição do que se considerava evidências do progresso das nações capitalistas. No entanto, Moysés Kuhlmann Júnior ressalta que estas mostras "apresentavam uma igualdade arquitetada, que de fato sublinhava as diferenças ao marcar com precisão o lugar de cada grupo social e de cada nação na ordem ali representada" (1996, p.27). As exposições e os congressos internacionais eram instâncias privilegiadas de difusão dos padrões assumidos como adequados para a civilização ocidental, constituindo, portanto, locais de construção das representações, do imaginário social, acerca do progresso e da posição ocupada pelos países no cenário internacional. $\bigcirc$ intuito de comparar os produtos e as próprias nações que participavam das exposições encontrou na estatística as bases consideradas confiáveis, porque ditas científicas, para se expressarem as diferentes "realidades". Desse modo, 
muito se avançou, durante esses eventos, na definição dos critérios, procedimentos e técnicas para a realização das estatísticas dos países. $\bigcirc$ Brasil tinha extremo interesse em apresentar-se no meio internacional como país civilizado e científico e precisava, então, assumir os padrões, bem como os procedimentos, valorizados nas mostras internacionais, entre os quais estava o desenvolvimento de estatísticas mais completas e confiáveis.

\section{CONTABILIZANDO OS INSTRUÍDOS: QUEM SE RESPONSABILIZA?}

Até 1870 não existia um órgão que fosse responsável pela realização e organização das estatísticas educacionais. Em I87| foi criada, pelo Decreto n. 4.676, a Diretoria Geral de Estatística, cuja atribuição principal, no entanto, era a realização dos censos decenais. Ainda assim, e mesmo que secundariamente, mencionava-se em seu regulamento explicitamente a responsabilidade dessa diretoria com a realização das estatísticas da instrução. Figurava entre seus objetivos a realização de estatísticas referentes "à população, ao território, ao estado político, intelectual e moral e ao agrícola, comercial e industrial" (Franca, 1947, p.624). Previa-se, naquela ocasião,

.... levantamento completo das escolas existentes no país, com discriminações relativas ao grau e à espécie, versando as indagações sôbre a constituição do professorado, a composição, por sexo, do discipulado, segundo a matrícula geral e a freqüência, esta sòmente em relação ao ensino primário. (Pessoa, 1946, p.257)

Porém, passado o Recenseamento de 1872, não foram providas condições para que a diretoria levasse adiante suas outras atribuições. Pessoa afirma a esse respeito que

...de pouco valia [...] criar a Diretoria Geral de Estatística e prescrever o âmbito das estatísticas que ela teria a missão de apurar e coordenar, desde que nenhuma providência fôra prevista para garantir a realização de uma boa coleta, com base na existência de fontes de informação operantes e na colaboração interessada dos Governos provinciais. (1946, p.256) 
Em vista dessas dificuldades, em 1879 a diretoria foi desativada pela Lei n. 2.940, sendo restaurada em 1890 pelo Decreto n. I I3-d, já na República, porém mais uma vez sem que the fossem dadas as condições suficientes para o adequado funcionamento.

Em 1897 a Diretoria Geral de Estatística passou por uma reformulação, definida no Decreto n. 2.768, com a finalidade de melhor conformá-la à execução do $3^{\circ}$ Recenseamento Geral do Brasil. Em 1907, pelo Decreto n. 6.628, esta diretoria foi mais outra vez reformada, sendo, então, entregue à direção de Bulhões Carvalho cuja atuação permitiu-lhe reagir contra a estagnação na qual se encontravam seus trabalhos e realizar obras consideradas notórias por seus contemporâneos. De acordo com José Quadros Franca, o plano esboçado pelo referido decreto, "não obstante as lacunas que continha, contribuiu para melhorar consideravelmente o serviço de estatística no Brasil" ( 1947, p.625). Os objetivos continuavam praticamente os mesmos definidos quando da sua criação, ainda no Império, mas o novo regulamento reestruturava os trabalhos da diretoria organizando quatro seções, cada qual incumbida de tratar de uma das atribuições do órgão. A $4^{\mathrm{a}}$ seção tinha de, entre outras responsabilidades, tratar da instrução pública e seus inquéritos deveriam "abranger não só o ensino primário, que constituía sua parte principal, como todos os demais ramos da cultura intelectual” (Franca, 1947, p.626). Essa seção foi entregue a Oziel Bordeaux Rego, que elaborou um plano para organizar nacionalmente as estatísticas educacionais. Tal intento foi considerado inviável por vários de seus colegas, visto que não existia nenhuma estrutura de coleta e sistematização previamente organizada e também inexistiam trabalhos anteriores nos quais se pautar. Essas dificuldades realmente se fizeram sentir, mas não impediram a realização da publicação Estatística Escolar de 1907, que, de acordo com Pessoa, "constitui um trabalho notável, o primeiro que no gênero se elaborou no Brasil em têrmos completos com referência ao território nacional" (1946, p.257). Esse trabalho foi o mais minucioso que se fizera até então, uma vez que trazia, pela primeira vez, as informações sobre a freqüência no curso primário, conclusões de curso e distinguia as escolas quanto à dependência administrativa, informações que não apareciam nos poucos levantamentos que já se haviam realizado.

No entanto, apesar dos bons resultados após a reorganização de 1907 , os trabalhos da diretoria foram decaindo em regularidade e quanto à qualidade de seu conteúdo. Pela análise de Pessoa, isso foi decorrência do "constante 
efeito das resistências do meio às iniciativas daquela repartição" (1 946, p.257). Pessoa indica que desde a sua criação, além da falta de recursos materiais e humanos, a diretoria ressentiu-se da "falta de meios para suprir, com sua ação direta, a ausência de cooperação do grande público, conseqüente à incompreensão reinante quanto às vantagens dos levantamentos numéricos por mais simples que fossem" (1946, p.256).

Mesmo não tendo a estatística educacional nesse período se desenvolvido muito mais do que nos momentos anteriores, o fato de pela primeira vez figurar explicitamente como objetivo e responsabilidade estatal evidencia certa preocupação do Estado em organizar a educação pautando-se em elementos técnico-científicos. A partir do final do Império, a estatística da instrução ocupava cada vez mais espaço nos discursos das figuras públicas interessadas na área educacional, no entanto as ações com vistas à organização dos levantamentos quantitativos eram pouco ou nada profícuas. Somente no início do século $X X$, já na República, começa-se a perceber a existência de iniciativas no sentido de realizar não apenas trabalhos estatísticos de uma ou outra região, mas antes de estruturar um sistema de coleta e tratamento dos dados numéricos sobre educação que estabelecesse procedimentos, definisse critérios e coordenasse as ações realizadas nos diversos estados brasileiros.

\section{ESTATÍSTICAS DE EDUCAÇÃO: A CRIAÇÃO DE UM ÓRGÃO ESPECIALIZADO}

Com a criação do Ministério da Educação e Saúde, pelo Decreto n. 19.402, de 14 de novembro de 1930, as estatísticas educacionais ganham novo impulso e mais uma vez alimenta-se a esperança de organizá-las nacionalmente. A criação do órgão surge como uma das iniciativas voltadas à transformação da realidade brasileira pretendida pelo movimento político de 1930 , que levou Getúlio Vargas à presidência da República, e foi uma das primeiras circunstâncias que colaborou para a estruturação de um serviço nacional de produção das estatísticas educacionais. Dentre as principais preocupações nos anos que se seguiram à organização deste ministério estava a realização de levantamentos estatísticos. Para que o novo órgão pudesse levar a efeito os objetivos para os quais havia sido criado, acreditava-se que era imprescindível a obtenção de dados que permitissem conhecer a situação na qual se encontrava 
a educação no país naquele momento. Mário Augusto Teixeira de Freitas informa que, em mensagem dirigida aos chefes dos governos regionais em novembro de 1932, o presidente da República Getúlio Vargas ressaltava

.... assentamento de um plano orgânico e suficientemente amplo, de medidas governamentais, em que estreitamente cooperem as três linhas de fôrça de nossa estrutura política, não será possível enquanto o país não conhecer exatamente, isto é, com atualidade, minúcia e verdade, o alcance da obra educacional que já se realiza, suas falhas, suas possibilidades e toda a extensão do esfôrço que ainda precisa empregar tendo em vista nossas profundas diferenciações geográficas e sociais. (apud Jardim, 1941, p. 1100)

Getúlio Vargas reforçava ainda que esse conhecimento só poderia "ser obtido através de estatísticas rigorosas e suficientemente compreensivas, que até agora não tínhamos ainda podido organizar, devido principalmente à falta de cooperação entre o Govêrno Federal e os governos regionais" (p. I l00).

No ano seguinte à criação do novo ministério, sua estrutura foi regulamentada pelo Decreto n. 19.560, de 5 de janeiro de 1931, sendo criada, no conjunto das diretorias que davam forma ao órgão responsável pela educação e saúde no país, a Diretoria Geral de Informações, Estatística e Divulgação. As atividades que estavam a cargo da $4^{a}$ seção da antiga Diretoria Geral de Estatística passaram a ser executadas por esse novo órgão. Era a primeira vez que no Brasil se criava um órgão cuja atribuição principal era tratar das estatísticas educacionais.

Em 1939 a Diretoria Geral de Informações, Estatística e Divulgação passou a chamar-se Serviço de Estatística de Educação e Saúde - Sees². Subordinado administrativamente ao Ministério de Educação e tecnicamente ao IBGE, o órgão tinha a atribuição de "levantar e coordenar a estatística geral das atividades educacionais, culturais e médico-sanitárias do país, bem como prover à respectiva divulgação" (Franca, 1947, p.633). Quanto à estrutura, funcionava

.... Serviço com uma seção administrativa e seis seções técnicas, das quais uma de estatística médico-sanitária, uma de inquéritos urbanísticos, uma de estatística

2. Em 1956 o órgão passa a chamar-se Serviço de Estatística da Educação e Cultura - Seec. Posteriormente foi incorporado ao Inep, tornando-se um de seus departamentos. 
das instituições culturais, uma de estudos e análises e duas exclusivamente dedicadas aos levantamentos escolares: a primeira - Seção de Estatística do Ensino Primário Geral - e a segunda - Seção de Estatística do Ensino Não-Primário. (Jardim, 1944, p.221-222)

Em 20 de outubro de 1944 foi aprovado pelo Decreto n. 16.915 o regimento do Sees, no qual constava a sua finalidade, de "levantar as estatísticas referentes às atividades educacionais, culturais, urbanísticas e médico-sanitárias do país, bem como promover, em publicações próprias, ou por intermédio do SD [setor de divulgação] e do IBGE, a divulgação dessas estatísticas" (Brasil, 1944, p.468).

Teixeira de Freitas, em artigo de 1943 publicado na Revista Brasileira de Estatística, procura evidenciar a estreita relação que viria a se estabelecer entre o Sees e o IBGE. Segundo o autor,

...a história do Serviço de Estatística da Educação e Saúde, só de três anos mais longa do que a do Instituto Brasileiro de Geografia e Estatística, têm-se desenvolvido, por assim dizer, paralelamente à do órgão centralizador da Estatística Brasileira e muitas vezes com ela se confunde, tanto na semelhança dos objetivos, como na consecução prática de determinados planos de trabalho. (Freitas, 1943a, p.235)

De acordo com Jardim, "o Sees encarrega-se de fazer a síntese geral e divulgar 'em bruto' as estatísticas concluídas que o IBGE e o Ministério da Educação também publicam; e o Inep procede à análise minuciosa e a comparações sucessivas dos resultados dessas estatísticas" (1944, p.229).

Ao Sees cabia a distribuição às repartições regionais do material de coleta dos dados e dos quadros destinados à apresentação dos números obtidos. No entanto, o órgão local podia optar por um questionário próprio e mais completo, no qual, além das informações requeridas pelo Sees, constassem outras de seu interesse. A partir de 1951 essa incumbência passou às mãos do IBGE, que adotou novos modelos de boletins. Foram, então, previstos dois tipos de questionários, o anual e o mensal, sendo facultado ao órgão regional adotar aquele que melhor se adequasse às suas condições. Jardim afirma que 
...a tudo proveram os órgãos regionais e o federal, fornecendo àquêles [estabelecimentos de ensino], ainda, quanto a todo o ensino primário, e, em alguns casos, aos empreendimentos educativos privados, livros de registro, fichas, boletins e fórmulas diversas, a fim de que, sem demora apreciável além do tempo imprescindível para concatenar os fatos registrados à medida que se produziam, se obtivesse a satisfação, pronta e correta, das indagações formuladas pela estatística. (1945, p.230-231)

Pessoa afirma que graças ao Sees melhorou muito a situação da documentação numérica acerca do ensino brasileiro. A esse órgão cabia a organização de informações acerca dos assuntos sob sua responsabilidade que contribuíssem com o Anuário Estatístico do Brasil, com a publicação $\bigcirc$ ensino no Brasil, com revistas científicas, boletins do Inep e outras publicações periódicas para as quais the fosse pedida colaboração. Segundo Pessoa, as numerosas publicações elaboradas por esse órgão sugerem "o extraordinário enriquecimento da documentação numérica concernente ao ensino no Brasil, quer se considere essa documentação em profundidade, quer se tenha em vista a multiplicidade dos aspectos perquiridos" (1946, p.255).

Também o Instituto Nacional de Estudos e Pesquisas Educacionais, criado em 1937 pelo Ministério da Educação, participou com significativa importância da produção, análise e publicação das estatísticas educacionais. Órgão oficial vinculado ao Ministério da Educação, demonstrou o Inep, desde sua origem, preocupação com a organização da, à época, esparsa documentação pedagógica. Ao Inep cabia formalmente, entre outras atribuições, a análise e interpretação dos dados fornecidos pelo Sees. No entanto, ambos os órgãos acabaram por realizar trabalhos tanto de coleta quanto de análise das informações quantitativas sobre educação.

\section{PADRONIZAÇÃO DAS ESTATÍSTICAS EDUCACIONAIS: AS DIFICULDADES DE COORDENAÇÃO DOS LEVANTAMENTOS REGIONAIS}

A promessa republicana tinha alimentado grandes expectativas no que se refere às questões educacionais. Acreditava-se que a educação, juntamente com a democracia e o federalismo, redimiria o país, colocando-o nos rumos do 
progresso. Apesar da crença na importância da educação para a consolidação da república democrática, pouco foi efetivamente realizado com vistas à expansão da escola popular nos primeiros anos da República. Na década de 1920 os próprios republicanos mostravam-se desiludidos com os rumos tomados pelo novo regime político, abrindo espaço para o ressurgimento da questão educacional associada à solução dos problemas nacionais. A corrente nacionalista, que então ganha relevo, "ao lado do combate à estrangeirização do Brasil, procura debelar o analfabetismo e difundir a escola primária, transformada num dos grandes problemas nacionais" (Nagle, 1977, p.262). Acreditava-se que a falta de instrução da população era a causa de todas as crises e, portanto, o principal problema do país, de modo que, se fosse expandida a escola elementar, seriam resolvidos os demais problemas.

Quanto à organização do sistema de instrução pública, a República acabou por consolidar a descentralização das responsabilidades referentes à criação e manutenção de escolas elementares, o que significava na realidade a dispersão de esforços entre os estados. De acordo com Fernando de Azevedo,

.... triunfo do princípio federativo, com a mudança do regime políico, não só consagrou mas ampliou o regime de descentralização estabelecido pelo Ato Adicional de 1834 e, jogando a educação fundamental (primária e secundária) do plano nacional para os planos locais, subtraiu à esfera do govêrno federal a organização das bases em que se devia assentar o sistema nacional de educação. (1958, p.117)

Assim, durante a Primeira República, apesar da intensificação das discussões educacionais e esperanças quanto ao poder redentor da educação, não se desenvolveu uma política de educação de abrangência nacional e se manteve o sistema dualista de escolas como no Império. A compreensão vigente acerca da estrutura federativa impedia que a União atuasse no nível primário de instrução, o que era entendido como ingerência no âmbito das atribuições estaduais. A maioria dos estados, por sua vez, não dispunha de recursos para instalar e manter escolas em adequadas condições de funcionamento. Desse modo, definiu-se um desenvolvimento da educação baseado nas condições de cada região do país e nas pressões locais, acarretando enormes diferenças de organização das escolas em cada estado da federação e significativas diver- 
sidades quanto à qualidade da educação ministrada nos diferentes sistemas de ensino.

Também nos levantamentos quantitativos sobre educação se fizeram sentir as conseqüências da organização federativa que se consolidou no país após | 889. Durante a Primeira República, ficou a cargo dos estados a realização das estatísticas, devendo cada qual produzi-las e enviá-las ao órgão central que tinha a incumbência de proceder às totalizações nacionais. Como os estados tinham concentrado muitos encargos, dispunham de poucas condições e escassos recursos para cumpri-los e como não lhes era evidente a importância dos levantamentos estatísticos, na maioria das vezes acabavam por não atender aos pedidos da Diretoria Geral de Estatística. A este respeito, Pessoa afirma que essa diretoria não apresentava

...condições precisas de vitalidade e de ânimo para enfrentar com vantagem a displicência das autoridades estaduais, indiferentes ao dever de cooperação com o Govêrno Federal, seja por simples incompreensão de seus dirigentes, seja pela impossibilidade de colaborar nos cômputos de interêsse nacional por não disporem os serviços respectivos de uma escrituração regular. (194 I, p. | 250).

Mesmo nos estados em que eram possíveis os trabalhos estatísticos, afirma Pessoa, que tais iniciativas "consubstanciaram-se em realizações desconexas pela disparidade dos planos a que obedeceram, concebidos uns à revelia dos outros, e todos à margem dos interesses superiores da nação" ( I 940, p.86). Os estados enviavam os dados numéricos organizados nas categorias que lhes parecessem mais adequadas e como não houvesse uma conformidade de categorias entre as diferentes regiões do país, a elaboração dos quadros totais tornava-se por vezes uma tarefa impossível. Várias tentativas de organização das estatísticas educacionais foram feitas e, ainda que esparsamente, vinham sendo realizados alguns levantamentos regionais acerca da instrução, "entretanto, o que se havia feito carecia de ordem, clareza, uniformidade. Havia, enfim, elementos, ora de alguns Estados, ora de outros e nunca uma estatística completa de todo o país" (Franca, 1947, p.625). Com vistas a solucionar esses problemas, a diretoria procurou empreender algumas iniciativas, no entanto, não obteve êxito na organização das coletas regionais e sistematização dos dados obtidos. De um lado, porque não havia, por parte dos estados, muita 
colaboração. A maioria dos estados não respondia aos apelos da diretoria para que Ihe mandassem dados educacionais. Os poucos estados que promoviam levantamentos regionais e os enviavam ao órgão central procediam de forma assistemática, ou, em outros casos, trabalhavam com dados incompletos e pouco confiáveis. De outro lado, a diretoria não contava com estrutura suficiente para realizar, ela própria, os levantamentos em cada região, o que Ihe permitiria prescindir da colaboração dos estados. Além disso, a diretoria tinha por atribuição organizar também as estatísticas de outros setores, o que representava uma insustentável divisão de esforços.

Entre as dificuldades que se interpunham à realização das estatísticas educacionais nacionais, a que mais se destacava era a dispersão demográfica, acrescida da enorme extensão territorial do país. Em entrevista concedida ao jornal A manhã, em 1943, Freitas sintetiza os obstáculos enfrentados pelas iniciativas no âmbito das estatísticas:

... dispersão demográfica, as dificuldades das comunicações, a incultura generalizada, o rudimentarismo ou inexistência dos registros públicos e privados, já não falando de outras condições desfavoráveis que o Brasil então oferecia à organização e à eficiência dos serviços de estatística, não permitiram grandes êxitos. Além disso, não houve continuidade nas tentativas empreendidas e os recursos dedicados à estatística foram sempre muito escassos. (1943, p.516)

Para que os dados sobre a situação do ensino fossem obtidos, era necessário que cada município recolhesse as informações acerca de suas escolas e as enviasse ao órgão central que, reunindo os números de cada localidade, faria as somatórias, construiria as tabelas e os gráficos desejáveis e estabeleceria as comparações necessárias. Nesse sentido, outra dificuldade se fazia sentir, a saber, a falta de padronização dos dados enviados ao ministério, o que impedia a realização de totalizações e o estabelecimento de relações entre os números dos diferentes municípios. A recém-criada Diretoria Geral de Informações, Estatística e Divulgação estava "compenetrada da necessidade de desenvolver o programa dos inquéritos e de se assegurar da máxima colaboração dos Governos regionais" (Pessoa, 1940, p.93) e, com vistas a esses objetivos, conseguiu que a Associação Brasileira de Educação - ABE - incluísse, entre os assuntos que seriam discutidos na sua conferência, "temas relativos ao problema 
da uniformidade das estatísticas escolares e à cooperação inter-administrativa necessária para consegui-la" (p.93).

A ABE vinha demonstrando igualmente preocupação com a organização dos dados numéricos escolares. Criada em outubro de 1924 por intelectuais cariocas, sob orientação de Heitor Lyra da Silva, incluíra entre os quatorze objetivos do seu plano de ação o de "organizar permanentemente a estatística da instrução no Brasil” (Jardim, 1944a, p. 12). De acordo com artigo publicado na Revista Brasileira de Estatística, podia-se perceber no âmbito da ABE as "graves advertências daquelas vozes autorizadas que, ao deter-se na apreciação do problema educacional brasileiro, condicionavam invariavelmente a sua exata fixação e seguro encaminhamento à existência de uma boa estatística escolar"

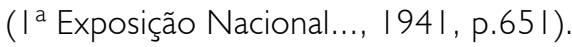

As Conferências Nacionais de Educação foram a principal instância de organização do movimento educacional da $A B E$ em âmbito nacional. A primeira dessas conferências aconteceu em 1927, à qual se seguiram outras anualmente. Marta Maria Chagas de Carvalho aponta que a representação desses eventos da ABE, durante a década de 1920, foi a de "festa ou certame a congregar altas autoridades e personalidades dotadas de notório saber e distinção social, prestigiadas pelos poderes públicos constituídos que neles são também prestigiados" (1998, p.308). As conferências eram vistas como festas cívico-nacionalistas onde se discutia a questão da educação brasileira visando à unidade nacional.

A partir do processo que ocasionou a ruptura da "política oligárquica" e levou Getúlio Vargas à presidência da República,

... as relações da Associação com o Estado modificar-se-iam, funcionando aquela, algumas vezes, como desdobramento do Ministério da Educação e, este, em outras, colocando seus serviços à disposição: convocando, por exemplo, por via dos Interventores, as delegações estaduais ao comparecimento à Conferência Nacional de Educação. (Carvalho, 1998, p.70-7I)

A $4^{\text {a }}$ Conferência Nacional de Educação se realizou em dezembro de 1930. Naquela ocasião, a distinção entre a ABE e o Ministério da Educação era uma linha tênue de difícil demarcação. Vários dos congregados da associação ocupavam cargos no novo governo. É o caso, por exemplo, de Teixeira de Freitas, que respondia pela Diretoria de Informações, Estatística e Divulgação, 
tinha claro interesse pela questão das estatísticas de educação e foi um dos principais organizadores do evento. Não por acaso, portanto, foi incluída entre as teses a discussão sobre a padronização das estatísticas, que grande significado político tinha para o ministério.

A pedido da diretoria foram inseridas as seguintes questões para discussão no evento da ABE:

$\ldots 4^{\mathrm{a}}$ Como se devem constituir os padrões brasileiros para as estatísticas do ensino, tanto particular como oficial, em todos os seus ramos?; $5^{\text {a }}$ Que registros devem ser criados, em que moldes e em que condições, para que as estatísticas escolares brasileiras possam ser levantadas nas requeridas condições de compreensão, veracidade e rapidez?; $6^{a}$ Que bases são aconselháveis para um convênio entre a União e as unidades políticas do país afim de que as nossas estatísticas escolares se organizem e se divulguem com a necessária oportunidade e perfeita uniformidade de modelos e resultados, em publicações de detalhe e de conjunto, ficando aquelas a cargo dos Estados, do Distrito Federal e do Território do Acre, e cabendo as segundas à iniciativa federal? (Jardim, 1941, p. 1097)

Assim, pelo Decreto n. 20.772, de II de dezembro de 1931, foi autorizada a convocação dos governos das unidades federadas para a $4{ }^{a}$ Conferência da $A B E$, onde se pretendia discutir conjuntamente com os representantes dos estados, do Distrito Federal e do Território do Acre os termos de um convênio para a uniformização das estatísticas de educação. Conforme mencionado, havia naquela ocasião uma compreensão bastante estrita acerca do funcionamento do sistema federativo. Os estados temiam que houvesse ingerência do poder central em suas jurisdições e, portanto, rejeitavam as propostas de ação conjunta com a União por suspeitarem que isso pudesse significar diminuição de sua autonomia. Os debates entre os participantes da conferência foram bastante prolongados até que se chegasse a um acordo sobre os termos do convênio a ser firmado. Cada unidade federada pôde contribuir trazendo à discussão suas necessidades e elucidando suas reais possibilidades de colaboração. Franca afirma que se procedeu, "dessa forma, a modificações e supressões de artigos, levando-se sempre em consideração as necessidades e as circunstâncias peculiares a cada Unidade da Federação" (1947, p.630). Ainda de acordo com Franca, "forjava-se ali nova mentalidade, baseada na compreensão de que os 
diferentes governos poderiam cooperar em benefício da Nação sem comprometer as respectivas autonomias" (p.630).

Em 20 de dezembro de 193 I foi aprovado pelo Decreto n. 20.826 o termo do Convênio Inter-administrativo de Estatísticas Educacionais e Conexas "que fixou em 27 cláusulas as normas para a sua execução, dispôs sôbre os encargos dos órgãos interessados quanto ao levantamento das estatísticas em um plano bastante desenvolvido" (Jardim, 194I, p. I099). De acordo com Jardim,

... a organização das estatísticas escolares brasileiras passou, portanto, a obedecer a uma bem assentada diferenciação de atribuições entre a União e as unidades federadas, tendente a que melhor se aproveitassem os esforços das repartições por elas responsáveis e se conseguissem, em toda a República, resultados não só homogêneos, mas também perfeitamente coerentes, capazes de exprimir, com minúcia e verdade, as condições gerais do país e de cada unidade federada, quanto a todos os ramos de ensino e aos vários aspectos apreciáveis do aperfeiçoamento e da cultura nacional. (1941, p. 1099)

Aos estados, ao Distrito Federal e ao Território do Acre foi atribuída, pelo convênio, a incumbência de realização das estatísticas referentes ao ensino pré-primário e primário (comum e supletivo). À União coube a realização dos inquéritos acerca do ensino profissional, especializado e semi-especializado, em todos os seus graus e categorias, além do ensino geral (excluindo-se nesse caso o pré-primário e o primário) tanto nos estabelecimentos públicos quanto nos particulares.

De acordo com a resolução do Conselho Nacional de Estatística que instituiu o Convênio Inter-administrativo de Estatísticas Educacionais e Conexas, seus objetivos eram

...uniformizar e coordenar todos os trabalhos oficiais de estatística educacional e conexos, de modo que [fosse] possível conhecer e divulgar rapidamente, com segurança, as condições gerais do Brasil [...] em um determinado ano, quanto a todos os ramos do ensino, bem como os vários aspectos apreciáveis do aperfeiçoamento da educação e da cultura nacional" (apud Fundação IBGE, 1941, Resol. n. I15, cláusula primeira). 
Desse modo foi possível sanar dois problemas que muito prejudicavam o adequado desenvolvimento das estatísticas educacionais. Por um lado, o acordo garantiu a colaboração dos estados com o órgão central, dividindo responsabilidades e conjugando esforços, assegurando assim a obtenção de dados nacionais sem uma centralização excessiva tanto de poder quanto de tarefas. Por outro lado, o convênio fixou normas garantindo a padronização dos dados de modo a permitir a realização de análises comparativas e a produção de quadros totalizando os números acerca da educação em todo o país. Assim, com o estabelecimento desse pacto político de cooperação entre as três órbitas de poder, "encaminhava-se, por fim, em têrmos definitivos, o problema da estatística educacional, de modo a obterem-se, por meio de uma inteligente coordenação de esforços, realizada em unidade de plano e com identidade de objetivos, resultados homogêneos, coerentes e atuais" ( ${ }^{a}$ Exposição Nacional..., 1941, p.65।-652).

Outra preocupação atendida pelo convênio dizia respeito à necessidade de inclusão dos dados acerca da educação brasileira nas publicações estatísticas internacionais. Visando a instaurar condições para se alcançar esse fim, o

...(Convênio de 1931, na sua cláusula XVI, letra d), estabeleceu que seriam encaminhados ao Instituto Internacional de Estatística os dados gerais das estatísticas educacionais e conexas, já adaptados aos modelos, recomendados pela Comissão Mista de Estatística Intelectual, constituída de representações daquele Instituto e do de Cooperação Intelectual da Liga das Nações, e aprovados na sessão que a primeira dessas organizações realizara no Egito, quatro anos antes. (Pessoa, 1946, p.259)

O Convênio Inter-administrativo das Estatísticas Educacionais e Conexas foi indicado por seus contemporâneos como uma iniciativa extremamente bemsucedida, que teria conseguido finalmente organizar estatísticas nacionais de educação mais completas e com regularidade. $\bigcirc$ acordo era freqüentemente mencionado como tendo sido "uma campanha vitoriosa e uma demonstração brilhante da eficiência do regime sob que se realizou - inédito até então - de mútuo entendimento e colaboração entre os governos federal e regionais" (Pinto, 1941, p.657). Pessoa indica, como exemplo da melhoria dos dados obtidos, a inclusão nos inquéritos de 
...elementos relativos às aprovações e à matrícula efetiva, os quais, sendo relevantes no estudo da escolaridade [...] não foram incluídos no plano previsto pelo regulamento de 187 I e não puderam ser contemplados no programa da estatística de 1907, restrito àquelas poucas indagações que, na época em que foi adotado, ofereciam possibilidades de reação favorável por parte das eventuais fontes de informação. (1946, p.259)

Dez anos depois de firmado o convênio, Zaíra Pinto reafirma os resultados positivos de tal empreendimento e ressalta que

...substituindo o resumido plano sob o qual eram anteriormente levantadas as estatísticas do ensino, são os resultados do Convênio, dispostos em densas séries e detalhadas discriminações, ano a ano apresentados pelo Serviço de Estatística do Ministério da Educação e Saúde ao estudo e consideração das autoridades oficiais e particulares ligadas ao assunto. (1941, p.657)

Apesar dos bons resultados decorrentes do convênio, havia ainda, na década de 1940, dificuldades principalmente com relação às fontes primárias de informação, ou seja, os municípios. Com o intuito de sanar esses problemas, em 1942 foram firmados os Convênios Nacionais de Estatística Municipal pelos quais os municípios concordaram em passar ao IBGE a responsabilidade pela administração de suas agências de produção das estatísticas.

Também por determinação do convênio pretendeu-se resolver o problema do conhecimento das instituições de ensino existentes mediante a definição da obrigatoriedade da "inscrição das instituições escolares nos órgãos oficiais competentes e os registros contínuos do movimento didático, a fim de que as estatísticas pudessem ser levantadas nas requeridas condições de compreensão, veracidade e presteza" (Jardim, 1945, p.229). A inscrição das instituições era uma necessidade antiga e muito básica, porque a abertura de novas escolas e o fechamento de outras, na maioria das vezes, não era de conhecimento da administração pública, de modo que nunca se podia saber o número de escolas em funcionamento. A falta de organização atingia também as escolas em sua organização burocrática. Muitas não controlavam os dados acerca do número de alunos que atendiam e não registravam o movimento no estabelecimento, ou seja, não sabiam quantos alunos tinham ingressado na instituição em cada 
ano, quantos dela se tinham evadido, a idade de seus estudantes etc. Com a decisão pelo convênio de registro permanente do movimento escolar, este passou a constituir uma das principais fontes de dados para as estatísticas. Desse modo, afigurou-se conveniente a uniformização desses registros pelo aprimoramento da escrituração já em prática em cada região. Aos poucos, foram se sucedendo vários atos administrativos, novas disposições e instruções com o fim de sistematizar e racionalizar os registros escolares básicos. Em 1946 , pela resolução n. 330, de 25 de julho, do Conselho Nacional de Estatística foi aprovada a adoção dos livros de "Registro Escolar", que deveriam ser utilizados por todos os estabelecimentos que ministrassem ensino primário. Em 1951, nova resolução do mesmo Conselho (n. 486, de II de setembro de 195I) determinou o aperfeiçoamento das estatísticas educacionais pela inclusão, nas coletas, dos dados obtidos nos livros de "Registro Escolar".

\section{CONSIDERAÇÕES FINAIS}

Pretendeu-se evidenciar a partir da sistematização aqui apresentada o modo pelo qual se desenvolveu o processo de organização e consolidação do sistema nacional brasileiro de coleta e tratamento dos dados estatísticos sobre educação. Embora a preocupação com a obtenção de dados quantitativos educacionais tenha surgido no período imperial, como parte de um esforço de construir a idéia da nação independente que então se pretendia formar, em termos objetivos pouco foi efetivamente realizado. Dos reclamos de algumas figuras públicas no século XIX e das iniciativas dispersas de algumas províncias/ estados até a consolidação de um sistema nacional de informações estatísticas educacionais no Brasil o percurso foi marcado por muitas instabilidades. $\bigcirc$ intuito de organização de um órgão responsável pelas informações numéricas em âmbito nacional caracterizou-se pelas idas e vindas e os esforços no sentido de imprimir mais consistência e regularidade aos números apresentados pelos estados não obtinham sucesso. Simultaneamente à criação e consolidação do próprio sistema escolar no Brasil foram sendo desenvolvidos os inquéritos que pretendiam descrever a abrangência desse processo e calcular o quanto faltava ser feito. Tal movimento ganhou significativo impulso após a criação no Ministério da Educação que centralizou esforços e racionalizou os métodos.

Se o período compreendido entre as últimas décadas do Império e o final da Primeira República testemunhou esforços e debates com vistas à cons- 
tituição de um aparelho burocrático central que respondesse pela coordenação e divulgação dos levantamentos estatísticos sobre educação realizados nas diversas localidades brasileiras, a década de 1930 deu lugar à consolidação da confiabilidade desses trabalhos. Relevante papel foi desempenhado pelo Convênio Inter-administrativo das Estatísticas Educacionais e Conexas, firmado em 1931, a partir do qual foi possível elaborar publicações sistemáticas acerca dos dados educacionais do país. Durante os anos 30, as estatísticas de educação começaram a desfrutar de significativa legitimidade entre pessoas envolvidas na gestão pública, passando a ser utilizadas e mencionadas com cada vez menos comentários indicativos de lacunas ou inconsistências técnicas.

\section{REFERÊNCIAS BIBLIOGRÁFICAS}

ANDERSON, B. Nação e consciência nacional. São Paulo: Ática, 1989.

AZEVEDO, F. O de. A Cultura brasileira: introdução ao estudo da cultura no Brasil, 3. 3. ed. São Paulo: Melhoramentos, 1958.

BOTELHO, T. R. População e nação no Brasil do século XIX. São Paulo, 1998. Tese (dout.) Faculdade de Filosofia, Ciências Humanas e Letras, Universidade de São Paulo.

BRASIL. Decreto n. 16.915, de 20 de outubro de 1944. Revista Brasileira de Estudos Pedagógicos, Rio de Janeiro, v. 2, n.6, p.468-474, dez. 1944.

CANDEIAS, A. (coord.) Modernidade, educação e estatística na Ibero-América dos séculos XIX e XX: estudos sobre Portugal, Brasil e Galiza. Lisboa: Educa, 2005.

CARVALHO, M. M. C. de. Molde nacional e fôrma cívica: higiene, moral e trabalho no projeto da Associação Brasileira de Educação (1924-1931). Bragança Paulista: Edusf, 1998.

CATANI, D. B; LIMA, A. L. G. Vigilância e controle: os Anuários do Ensino do Estado de São Paulo e a história do trabalho docente no Brasil (1907-1937). In: CATANI, D. B.; BASTOS, M. H. C. (orgs.) Educação em revista: a imprensa periódica e a história da educação. São Paulo: Escrituras, 2002. p. $155-172$.

EXPOSIÇÃO NACIONAL DE EDUCAÇÃO E ESTATÍ́STICA, I. Revista Brasileira de Estatística, Rio de Janeiro, n.7, p.65I-656, jul./set. 194I.

FARIA FILHO, L. M. de; BICCAS, M. de S. Educação e modernidade: a estatística como estratégia de conformação do campo pedagógico brasileiro (I 850- 1930). Educação e Filosofia, v. I4, n.27/28, p. 175-20I, jan./jun.- jul./dez. 2000. 
FARIA FILHO, L. M. de; NEVES, L. S.; CALDEIRA, S. M. A Estatística educacional e a instrução pública no Brasil: aproximações. In: CANDEIAS, A. (coord.) Modernidade, educação e estatística na Ibero-América dos séculos XIX e XX: estudos sobre Portugal, Brasil e Galiza. Lisboa: Educa, 2005. p. 219-238.

FARIA FILHO, L. M. de; RESENDE, F. M. História da educação e estatística escolar. Revista Brasileira de Estudos Pedagógicos, Brasília, v. 80, n. 195, p. 197-21 I, 1990.

FOUCAULT, M. Dits et écrits, 3. Paris: Gallimard, 1978. La "Gouvernementalité", p.635-657.

FRANCA, J. Q. A Estatística educacional no Brasil. Revista Brasileira de Estatística, Rio de Janeiro, n.30-31, p.624-634, abr.-set. 1947.

FREITAS, M. A. T. de. Os Cinco últimos septênios da evolução estatística brasileira. Revista Brasileira de Estatística, Rio de Janeiro, n. I 5, p.5 I5-530, jul./set. 1943.

O Órgão de estatística do Ministério da Educação e Saúde, antes e depois do IBGE. Revista Brasileira de Estatística, Rio de Janeiro, v. 4, n. I4, p.235-248, abr./jun. I 943a.

FUNDAÇÃO INSTITUTO BRASILEIRO DE GEOGRAFIA E ESTATÍSTICA. O IBGE e a educação, 2. São Paulo, 194I.

Metodologia do censo demográfico de 1980. Rio de Janeiro, 1983.

GIL, N. de L. A Educação nos censos populacionais brasileiros ( 1872 - 1960). In: CANDEIAS, A. (coord.) Modernidade, educação e estatística na Ibero-América dos séculos $X I X$ e $X X$ : estudos sobre Portugal, Brasil e Galiza. Lisboa: Educa, 2005. p.273-287.

Razão em números: a presença das estatísticas nos discursos educacionais divulgados na Revista Brasileira de Estudos Pedagógicos (1944-1952). São Paulo, 2002. Dissert. (mestr.) Faculdade de Educação, Universidade de São Paulo.

INSTITUTO BRASILEIRO DE GEOGRAFIA E ESTATIÍSTICA, O. Revista Brasileira de Estatística, Rio de Janeiro, n. 19, p.387-4I3, jul./set. 1944.

JARDIM, G. A Coleta da estatística educacional. Revista Brasileira de Estudos Pedagógicos, Rio de Janeiro, v. 2, n.5, p.221-230, nov. 1944.

A Coleta da estatística educacional, 3. Revista Brasileira de Estudos Pedagógicos, Rio de Janeiro, v. 4, n. II, p.229-250, maio 1945.

A Missão do órgão estatístico da educação e saúde. Revista Brasileira de Estatística, Rio de Janeiro, n.8, p. I045- I I I8, out./dez. 194 I.

Rumos da organização estatística brasileira: coletânea de documentos sobre a origem, evolução e atividade dos serviços estatísticos brasileiros. Rio de Janeiro: IBGE, 1944a. 
KUHLMANN JÚNIOR, M. As Grandes festas didáticas: a educação brasileira e as exposições internacionais (I 862-1922). São Paulo, 1996. Tese (dout.) Faculdade de Filosofia, Ciências Humanas e Letras, Universidade de São Paulo.

LUGLI, R. S. G. Representações do nacional e do educacional nas estatísticas educacionais brasileiras do ensino primário. In: CANDEIAS, A. (coord.) Modernidade, educação e estatística na Ibero-América dos séculos XIX e XX: estudos sobre Portugal, Brasil e Galiza. Lisboa: Educa, 2005. p.239-255.

MARCíLIO, M. L. A População do Brasil em perspectiva histórica. In: COSTA, I. del N. (org.) Brasil: história econômica e demográfica. São Paulo: Instituto de Pesquisas Econômicas, 1986. p. II-27.

NAGLE, J. A Educação na Primeira República, 2. In: FAUSTO, B. (org.) História geral da civilização brasileira: o Brasil Republicano - sociedade e instituições ( 1889 - 1930). São Paulo, Rio de Janeiro: Difel, 1977. t.3, cap.7, p.259-29l.

PESSOA, H. E. A. A Cooperação disciplinada e os recentes progressos da estatística no Brasil. Revista Brasileira de Estatística, Rio de Janeiro, n. I, p.86-99, jan./mar. 1940.

A Estatística educacional no Brasil. Revista Brasileira de Estatística, Rio de Janeiro, n.26, p.255-260, abr.jun. 1946.

A Estatística escolar em 1907. Revista Brasileira de Estatística, Rio de Janeiro, v.2, n.8, p.1247-1258, out./dez. 1941.

PINTO, Z. A Estatística do ensino primário segundo o convênio de 1931. Revista Brasileira de Estatística, Rio de Janeiro, n.7, p.657-666, jul./set. I 94I.

POPKEWITZ, T.; LINDBLAD, S. Estatísticas educacionais como um sistema de razão: relações entre governo da educação e inclusão e exclusão sociais. Educação \& Sociedade, v.22, n.75, p. III- |48, 2001 .

SOUSA, C. P. de. Os Organismos internacionais e o campo educacional: as posições do Brasil e de Portugal nas estatísticas da UNESCO (1946-1972). In: CANDEIAS, A. (coord.) Modernidade, educação e estatística na Ibero-América dos séculos XIX e XX: estudos sobre Portugal, Brasil e Galiza. Lisboa: Educa, 2005. p. 17-52.

SKIDMORE, T. E. Uma história do Brasil. 3. ed. São Paulo: Paz e Terra, 2000.

VIANNA, O. Resumo histórico dos inquéritos censitários realizados no Brasil: recenseamento do Brasil, 1920. São Paulo: IPE/USP, 1986. (ed. fac-similar)

Recebido em: maio 2006

Aprovado para publicação em: janeiro 2007 